\title{
Serious Games are a Serious Tool for Team Research
}

\author{
Michael D. Coovert ${ }^{1}$, Jennifer Winner ${ }^{2}$, Winston Bennett Jr. ${ }^{3}$, David J. Howard ${ }^{4}$ \\ ${ }^{1}$ University of South Florida, coovert@mail.usf.edu \\ ${ }^{2}$ Air Force Research Laboratory, jennifer.winner.1@us.af.mil \\ ${ }^{3}$ Air Force Research Laboratory, winston.bennett@us.af.mil \\ ${ }^{4}$ University of South Florida, davidhoward@mail.usf.edu
}

\begin{abstract}
Serious games are an attractive tool for education and training, but their utility is even broader. We argue serious games provide a unique opportunity for research as well, particularly in areas where multiple players (groups or teams) are involved. In our paper we provide background in several substantive areas. First, we outline major constructs and challenges found in team research. Secondly, we discuss serious games, providing an overview and description of their role in education, training, and research. Thirdly, we describe necessary characteristics for game engines utilized in team research, followed by a discussion of the value added by utilizing serious games. Our goal in this paper is to argue serious games are an effective tool with demonstrated reliability and validity and should be part of a research program for those engaged in team research. Both team researchers and those involved in serious game development can benefit from a mutual partnership which is research focused.
\end{abstract}

Keywords: Serious games, team research, teams, simulations, game engines

\section{Overview}

In many areas there has been an ever-increasing application of simulations and serious games. Two of the most popular domains are education and training. We believe a third area-research, and in particular team research - can benefit greatly through the use of serious games. There are many obstacles that historically researchers in the team area have faced, including exorbitant development costs for suitable software, inferior graphics that limit fidelity of the simulation, and difficulty with capturing team performance measures; to name but a few. Advances in game engines (e.g. CryEngine, Unity, and Unreal Engine) have lessened many of the problems associated with these obstacles. Thus it is time to earnestly consider the utility of serious games for the challenging area of team research.

In this article we begin by reviewing teams and candidate behaviors and competencies for team performance. Next, we describe the use of serious games in education and training and point out how serious games have been successfully utilized in these areas for research. We also provide the reader with game engine requirements and methodological considerations relevant for those conducting research via the gaming methodology. Our conclusion is a call for the application of serious games in team research, in that serious games allow for the investigation of team constructs not easily researched through traditional means. Developers of serious games would also benefit from the field of team research as the application of serious games allows the researcher to maintain rigorous standards for internal validity, external validity, and generalization of findings; while thoroughly exploring the criterion space of effective performance in teams.

\section{Teams}

Organizations continue to embrace teams as an effective strategy for dealing with the everincreasing intricacies of economic competition and survival [1]. A team is described as an interdependent group of individuals with complementary skills working toward shared goals. 
Teams are found in situations with complex or creative tasks and environments requiring multifaceted decision-making. Teams are also utilized when the situation is variable, requiring the team to adapt to changing external conditions. Due to these factors, teamwork forces individuals in the team to utilize various process skills, including (but not limited to): communication, monitoring, coordination, and feedback.

Virtual teams are ones whose members are dispersed, often geographically and/or temporally [2-4]. Due to this distribution in space and time, individuals utilize technology to communicate, coordinate, collaborate, and engage in task-work and teamwork behaviors. While many of the constructs that typify effective face-to-face teams are also relevant in virtual teams, little is known about the importance of constructs influencing behavior in virtual teams. For an example of an attempt to rectify this shortcoming, Pavlova et al. [5] are investigating the role of trust in virtual teams and how trust is impacted by such factors as team performance, effectiveness, and negative information.

Regardless of whether team interactions occur in a face-to-face or virtual context, it is important for team members to utilize effective team behaviors and team competencies. Research on teams is thriving and while there are a variety of typologies to summarize this research, we provide an integrated survey of the essential behaviors and competencies found across the literature on team research. Although extensive, our review of constructs and competencies in the area is not meant to be exhaustive; rather it is intended to provide the reader a framework and starting point for further focus in team performance research.

\subsection{Essential behaviors and competencies found in teams}

There are many ways to partition the criterion space associated with team performance, and certainly no shortage of authors who put their unique spin on the topic. Our approach is to provide the reader with several of the major typologies in order to illustrate the richness and also to provide a sense of the construct content, which must be measured by team researchers. We organize the research into the following five typological areas: components of teamwork, team processes, team knowledge, adaptive performance in teams, and those behaviors often relevant to the military. We now provide a description and exemplars of each area.

\subsection{Components of teamwork}

Components of teamwork are considered to be the fundamental building blocks of those factors that separate individual task work from teamwork [6]. Utilizing a multimethod approach, Brannick, Roach, and Salas [7] focused on dyads performing an aircrew task. Their findings reveal that communication and team process are the two critical dimensions of teamwork. Communication focused on providing information in the form of instruction or commands, volunteering information, asking questions, and making off-task comments (e.g., jokes). Team processes involve such factors as the spirit of the team (esprit de corps), the extent of interpersonal cooperation and technical coordination, and the quality of information when giving and receiving suggestions.

Dickenson and McIntyre [8] developed a more extensive perspective of team components. Their approach includes team orientation (spirit) in which members assigning a high priority to goal accomplishment and a willingness to participate in all aspects of team goal attainment. Team leadership describes an individual's willingness to listen to team member concerns and also to explain to each member what is needed from that individual for goal attainment. Communication is similar to the description utilized by Brannick et al., with a focus on verifying information and utilizing a positive exchange to ensure understanding. Monitoring recognizes an individual being aware of other team member's performance and taking action in those situations of task overload; monitoring also allows for one team member to identify when another is performing a task incorrectly. The Dickenson and McIntyre typology recognizes the importance of feedback, and describes it as responding to other members' requests for performance information and accepting strategies or suggestions for changes in task work (e.g., in order to perform a task more efficiently). Dickenson and McIntyres' final component is coordination, which is used to describe the passing of performance-relevant data to other members in an efficient manner, and facilitating the performance of another team members' job. For researchers focused on teams, the components of teamwork described above lay the foundation of what to identify and measure. 


\subsection{Team processes}

To understand how a team performs one must be able to model its actions over time [9-11]. Several researchers have solidified this idea and developed representations of team processes. Marks, Mathieu, and Zaccaro [12] proposed a temporally based structure with three primary processes termed: transition, action, and interpersonal. Drawing upon the Marks et al. research, LePine et al. [13] examined 138 previously published papers. Utilizing meta-analysis and confirmatory factor analysis, these authors claim statistical support for the structure developed by Marks et al., which we now describe.

Transition processes consists of analyzing the mission, specifying goals, and formulating a strategy. Action processes center on monitoring progress toward the goal, monitoring the system and team members, and coordinating actions. Interpersonal processes are concerned with managing conflict in the team, motivating teammates, and managing affect (emotions).

Thus, team processes deal with actions and activities that are part of the team. The identification and measurement of these processes are an important component of team research and must be captured by a serious game when being utilized for research.

\subsection{Team knowledge}

There is considerable work in the area of team knowledge and team situational awareness. As researchers have explored various conceptualizations and corresponding methodological considerations related to the measurement of team knowledge, a significant amount of attention has been paid to the overlap of, versus the distributed nature of team member knowledge [6, 14-18]. Instead of reviewing the entirety of the literature we refer the reader to two papers in the area [6, 14] that provide a literature review, identify the key issues, and provide an empirical illustration.

Team knowledge is defined as the assortment of task- and team-related knowledge held by teammates and their collective understanding of the situation confronting the team [14, 19]. Team knowledge is considered to have two components: the team mental model and the team situation model. The difference between the two can be described in terms of duration.

The team mental model is understood to be long lasting and exists prior to task performance. It is acquired primarily through prior experience and training. The team mental model consists of a variety of content, including both specifics of the task work performed by individual team members as well as aspects of teamwork (the components and processes described earlier). It consists of knowledge in a variety of forms, such as declarative, procedural, and strategic; and it functions as a collective base of knowledge for the team, leading to common and shared expectations among and between team members.

On the other hand, the team situation model is ephemeral. It is situation specific and as such is dynamic and fleeting. It is acquired during the task and utilizes constructs from the team mental model and world cues. The function of the team situation model is to assist team members in interpreting the situation in a common and compatible fashion.

Understanding and measuring team knowledge and its two components is an essential aspect of many research programs interested in team performance. Capabilities of serious games to measure team knowledge through continuous monitoring, automatic stimuli presentation, and response measurement, argue for serious games to be used as a tool in team research.

\subsection{Adaptive performance in teams}

One hallmark of effective teams operating in dynamic environments is an ability to adapt to changing situations. Ineffective teams lack this ability to self-modify to the demands of the changing environment. Rosen et al. [20] provide a review of the empirical, theoretical, and methodological literatures on team adaptation and the input-throughput-output model of a team proposed by Burke et al. [21]. The model consists of: specific characteristics brought to the team by individual members; an adaptive cycle of assessing, planning, learning, and feedback; emergent states such as team knowledge; and adaptation characterized by team information and modification.

Various behavioral markers are identified with the team adaptability process, specifically: coordination, back-up behavior, reactive-conflict management, affective management, mission analysis, goal specification, three types of strategy formulation (deliberate-, contingency-, and reactive-strategy planning), role differentiation, cue recognition, meaning ascription, communication, team member and systems monitoring, recapping, and finally reflecting. Specific 
behavioral markers for each process are provided in their Table 1 (pp. 115-116). For the most part, individual components of these processes are found across the other models reviewed here. We provide their framework as it specifically addresses team adaptability in dynamic environments, a key aspect to success in today's workplace--both military and civilian.

Rosen et al. derive six guiding principles that capture the core features of team adaptation and these can be used to inform measurement of the performance construct. The principles focus on capturing: 1 . bottom-up changes in team performance, 2 . top-down changes in strategy that impact team performance, 3. a team's recognition of a need for change, 4. the team's ability to self-assess, 5. what team members are thinking and feeling in a dynamic manner, and 6. a profile of team adaptation over time. Through employing these six guiding principles, the researcher can be assured the important aspects of team performance are identified, measured, and incorporated into the serious game.

\subsection{Team behaviors often relevant to the military}

Many jobs in the military are team based (e.g., air crew, ship firefighting team); as such, the military has had a foundational interest in teams. One of the early influential pieces written on the topic of team performance was authored by Tuckman [22] who, after studying 50 published papers on stages groups evolve through over time, identified four sequential processes through which groups progressed: Forming, storming, norming, and performing. Forming is the first stage and it deals with the group's orientation, testing, and dependence. The second stage, storming, is characterized by conflict and polarization around interpersonal issues. Norming occurs next and is typified by the feelings of in-group cohesiveness, development of group standards, and the adoption of group roles. Finally, there is performing, in which interpersonal structure becomes the tool governed by task activities. Structural issues are resolved and roles become adaptable to task constraints and supportive of task accomplishment.

Building upon this work by Tuckman [22], Morgan, Glickman, Woodward, Blaiwes, and Salas [23] developed a model of team evolution and maturation in the context of the Navy. Their model keeps the same general format as Tuckman's but elaborates upon it, inserting into the model Pre-forming, in which task assignments are made and issues of group reputation are considered. The next three constructs are those of Tuckman. Forming is focused on task orientation and testing for acceptance. Storming centers on emotional responses and intragroup conflict. Norming addresses group cohesion and the exchange of relevant interpretations. Morgan et al. break performing into two distinct pieces. The first, Performing I focuses on the emergence of solutions, functional role relationships, framework and role adjustment. Performing II is concerned with the drive to completeness, role fulfillment, delivery of the work product, and adjustment to environmental demands. A concluding piece to their model adds deforming; which is task withdrawal and exiting the group.

The final model of team performance we describe was developed studying aircrews. Originally presented in Prince and Salas [24], the authors reviewed research and training programs across the Army, Navy, and Air Force for cockpit teams. Fowlkes, Lane, Salas, Franz, and Oser [25] utilized the behaviors to develop a team training program for aircrew coordination and validated it on military helicopter pilots. The list is comprised of 42 critical skill behaviors subsumed under seven skill areas. The skill areas consist of the following. Mission analysis involves defining mission requirements, devising plans, and critiquing them. Adaptability/flexibility refers to the ability to modify behavior in order to fit the demands of the situation. Leadership centers on structuring tasks when necessary; seeking input, keeping members informed, and providing feedback on performance. Decision-making addresses gathering and validating information, anticipating consequences of decisions, and providing rationale for decisions. Assertiveness denotes asking questions, providing suggestions and opinions, confronting ambiguities, and advocating for a particular course of action. Situational awareness is demonstrating cognizance of task performance and the performance of others; noting deviations, identifying potential problems, and demonstrating ongoing awareness of mission status. Finally, there is communication which encompasses providing information when required or asked, using standard terminology and repeating or acknowledging information when appropriate, being concise, and using nonverbal communication when appropriate.

In addition to modeling team performance, the military was one of the first adopters of using serious games to measure team behavior, and simulations are now considered an essential component of the military's $21^{\text {st }}$ century defense [26]. One of the first simulations, America's Army: Operations, was originally conceived as a tool to introduce individuals to the values and 
goals of the United States Army [27] and to assist the U.S. Army with recruitment of volunteers [28]. Today, America's Army and others U.S. Army-produced simulations have evolved into an effective tool for the military to study teams, including a large-scale study that used America's Army to help combat troops navigate difficult terrain [28, 29].

The military's ongoing commitment to serious games is evidenced in their recent success at the 2016 Serious Games Showcase \& Challenge, where U.S. Army STARS Element -Fun with Chemistry won best mobile serious game, and the U.S. Army Research Laboratory / USC Institute for Creative Technologies-produced simulation USC Standard Patient, received the award for the best government developed serious game [30].

\section{Highlights of serious games}

We consider serious games those computerized games and advanced video graphics systems utilized for non-entertainment purposes and whose focus is on learning and training [31] or educational and behavioral change [32]; and we now extend this definition to include research. In their discussion of serious games, de Freitas and Ketelhut state that these games often have lofty ambitions and the field is "...fortunate that some far-sighted funding agencies such as the US National Science Foundation, the UK Technology Strategy Board, and the European Commission, have identified the power of games not only to engage and motivate but also to solve world-scale problems and make significant and important behavioural and social changes to improve our lives, work and study." (p. 2). While there is agreement on the importance of serious games, the appropriate label for the methodology is under discussion. Crookall [31] challenges the label used for the serious gaming discipline, preferring the term "computerized simulation/game for training or learning" (p. 905) over that of serious games. Similarly, de Freitas and Ketelhut note the parallel emergence of an academic field focused on serious games, and although it is currently distributed over many disciplines with many titles, they nominate Game Science as the unifying label.

Many consider the inauguration of serious games to harken back to business games and their application in the corporate world. Greco, Baldissin, and Nonino [33] note the first organizational game (MONOPOLOGS; [34]) was utilized by the Air Force to train inventory managers; shortly there after the first widely known business game was released. The first book [35] on serious games was published and was followed shortly there after by conferences such as the Association for Business Simulation and Experiential Learning (ABSEL) allowing researchers to present evidence for how business games impact aspects of corporate performance, influence teaching in management courses, and determine what individuals in these simulations actually learn [36].

More recently, Greco et al. [33] provided a taxonomy for classifying business games. Their taxonomy includes five macro-categories (p. 657): 1. Environment of application (characteristics of the games spatial and temporal environment); 2. Design elements of the user interface (characteristics of the user interface); 3. Target groups, goal objectives, and feedback (characteristics of the target and reinforcement mechanisms); 4. User relation/community (relational characteristics of the game); and 5. Model (characteristics of the simulation model within the game). The authors hope the taxonomy will serve to develop a global database to be built collaboratively by business game users and developers. Additionally, for those readers interested in learning about the prolific authors and topics in the area, see [37] who utilized research profiling on bibliographic data available from 40 years of publications in the area.

\subsection{Games versus simulations}

It is worth taking a moment and considering the relationship between simulations and games, in that the labels are often used interchangeably [38]. Adroitly argued, [39], state the difference between the two is found in their essential attributes. A simulation is "... a simplified, dynamic and accurate model of reality..." (p. 253) and is often used in a learning context. A game, on the other hand, is a fictitious or artificial situation in which the player is expected to perform. Players in a game are often put in a position of conflict, either against an opposition force or even against one another. It is worth noting, however, that Sauvé et al. acknowledge simulation games. Although they do not discuss the concept directly, it is likely their use of simulation games falls into our category of serious games.

Another definition of a game is provided by Pohl and Walker [40] who work with game technology for training. Although they do not use the label serious game, their description is consistent with our use. Pohl and Walker define a game as a structured activity whose key 
components include rules, interactions, challenges, and goals. As such, a game is not the hardware and software but rather the experience the user has while interacting with the system. This cognitive representation involves mental and physical simulations of the real world and while interacting in this space players acquire basic skills. A central goal regarding serious games is to determine the effectiveness of the simulation. That is, does it perform as intended and do the outcomes generalize beyond the playing context? One way developers of serious games can increase simulation effectiveness is to gamify existing training and educational material.

\subsection{Gamification}

Gamification is defined as "The use of game elements and game-design techniques in non-game contexts" [41, p. 21]. More specifically, "gamification" is used to describe initiatives in which elements of game design are applied, as opposed to the use of game-based technology, for use in non-game applications [42]. In other words, the use of a game engine does not alone qualify as gamification. Largely, efforts involving gamification are undertaken with the intent to engage, incentivize and/or motivate users of a system [43] through the use of tools such as real-time feedback, and rewards [44, 45]. Recently Landers and Landers [46] explicitly tested aspects of gamification on academic performance and found support for learning enhancement through gamification.

Focusing primarily on gamification, the Serious Game Design Assessment Framework [47] consists of six key design elements. The first is purpose (designers' intent), on impacting players beyond the play of the game itself; for example, to teach the players about some content area. Secondly is content \& information, which refers to the declarative and procedural knowledge used in the game. Thirdly is the establishment of rules that define user behavior and the methods whereby a player interacts with the world. These are complex [48] and drive the interaction with the game. Mitgutsch and Alvarado [47] label the rules and methods as game mechanics. Fourthly is the introduction of the fictional worlds and stories provided by the fiction and narrative. Linear versus nonlinear play is outlined and the story may change as the player proceeds through levels or accomplishes goals. The fifth evaluative criterion is aesthetics and graphics developed for the visualization and element display in the game. The sixth and final evaluative component is framing. The goal of framing is to target the key elements of the game on the focal group. One often-overlooked design principal is to present the game framed to the play level of the participants. If an incorrect level of play is implemented by the designers (e.g., savvy, when in fact the players are novice), the frustration (boredom) experienced by users will contaminate and confound the outcomes.

\subsection{Serious games in education and training}

We now take a closer look at the role of serious games in individual learning and their application in training, as interest in utilizing serious games in an education or training context has been on the rise [49]. Taken at the broadest level, a serious game might be utilized in any context where learning or training is the goal. The extent to which occurs can be assessed via an examination of the literature. Several surveys have been published on the topic and here we cite an illustrative few. The first, by Connolly et al. [50], describes an extensive review and these authors identified several key learning outcomes associated with serious games. These outcomes include those targeting changes related to: affect and motivation, behavior, knowledge acquisition and understanding, motor skills development, perceptual and cognitive improvement, and social/soft skill outcomes. Furthermore, a recent study found support for serious games as an improvement over more traditional methods when on-the-job task performance is an outcome of the training received from the serious game [51].

Sitzmann [52] presents a comprehensive meta-analysis on the effectiveness of simulation games for training. Relative to a comparison group, individuals trained via computerized simulations had higher levels of procedural and declarative knowledge, better retention, and higher levels of self-efficacy. In examining the findings across studies, Sitzmann identified that, relative to the comparison group, trainees learned more when: the material was actively presented to them; the simulation allowed unlimited access; and it was provided as a supplement to other instructional methods -- as opposed to a stand-alone method. If, however, the comparison group received instruction in a format that actively engaged them, the simulation group underperformed the comparison group. So merely having delivery of content is not enough for a simulation or serious game to effectively impact learning. See Bedwell et al. [53] for principles and aspects of 
gamification associated with learning, and Landers [54] for development of a theory of gamified learning based on Bedwell et al.'s taxonomy.

\subsection{Serious games and research}

Our goal is to identify those attributes of serious games that make them an effective research tool. Within a serious game there are three areas that must be evaluated: the validity of the simulation charged with representing the real-world phenomenon of interest; the pedagogical component associated with constructs to be learned; and the gamification aspect of the system tasked with incentivizing and motivating the players. Evaluative frameworks are provided by Ghannem [55] and Mayer et al. [56] who argue the only way for teachers and trainers to know if the serious game being utilized is effective or not is to have a set of explicit game design characteristics linked to detailed learning objectives, such as Bloom's taxonomy. These authors, along with an empirical assessment of the approach, provide several measurement/evaluation forms.

Mayer et al. also developed a model with methods for assessing serious games and game based learning (p. 512). The strategy aids with assessing reliability utilizing standard scales (e.g., checklists), in addition to reporting interrater reliability. Furthermore, the content of the scales provide an evaluation of the face and construct validity of the game. Taking the discussion of measurement even further, de Klerk, Veldkamp, and Eggen [57] argue it is important to move beyond simple pre- and post-test designs when evaluating serious games. They present a Bayesian network that can be applied to gain a full understanding of an individual's performance in serious games.

As can be gleaned from our review, there is a plethora of available methods for serious games. These range from guiding principles [58] through traditional experimental designs [59] and emerging techniques such as confirmatory factor analysis and structural equation modeling [60], graph theory and Petri nets [9], and Bayesian networks [57]. Using the appropriate methodological and statistical tool for the research task at hand, we argue it is important to assess the reliability and validity of serious games. This allows for the development and extension of serious games to the rich and often problematic arena of team research.

There have been several calls for additional research on serious gaming, for example [31] surveyed the field and challenged serious game designers to conduct additional research (e.g., on the importance of debriefing). Additionally, [61] discuss a series of papers providing examples of research methodologies (e.g., ethnography, physiological measures) appropriate in the context of serious gaming. Their argument is essentially that measures are game dependent and need to reflect the constructs of interest. de Caluwe, Geurts, and Kleinlugtenbelt [62] review the application of gaming and simulations for policy development and implementing change in organizations. Some lessons learned from their study of projects in these two areas include the points that games: are quasi-experiments and as such have advantages and limitations; manipulation checks are important; and if control groups are used ethical issues related to depriving learning opportunities to participants in control conditions must be addressed.

Finally, it is important to mention the work of Eladhari and Ollila [63] who argue that regardless of the games focus, it is essential for designers to iteratively build and test it in order to fully understand the play dynamics and experiences of individuals within the serious game. Said another way, if the purpose of a serious game is to be used as a tool for research, designers must ensure the validity of the constructs of interest and the reliability of their measurement. Reliability can be addressed, in part, through the use of parallel forms of scenarios [64], while construct validity is determined via statistical methods such as multitrait-multimethod [65, 66] and confirmatory factor analysis $[67,68]$. These research issues strike at the heart of team research, an area where it is often difficult to define constructs and operationalize them such that it is possible to statistically assess them in a meaningful fashion. We believe serious games, used as a method and aligned with an appropriate statistical procedure will provide the scientific rigor required for team research.

\section{Advantages of utilizing serious games for team research}

The development of gaming and game engines have made remarkable advances since the introduction by Rand [34] of MONOPOLOGS. Computerization provided the greatest leap forward, however, it was not a panacea in and of itself. Some areas experienced growing pains and needed further development, but today's game engines (e.g., CryEngine, Unity and Unreal as 
exemplars) have overcome initial shortcomings. Equipped with the review of both the serious games and team research literature presented above, we now describe a set of requirements when utilizing serious games for team research.

\subsection{General areas of improvement}

The first area of improvement that makes serious games attractive for team research is the amount of effort and cost related to development and task modification. Early simulations and games were typically single purpose designs and were not easily altered. If modifications were required to instantiate a change in a condition or scenario, programming hours were required often at considerable expense. An example of such a system is the game Space Fortress. Today's game engines, however, have advanced in order to reduce the overall production/programming time. As a result, the resources required have been drastically reduced for content authoring, the ability to change elements, and add events and entities in scenarios. Flow-graph capabilities within game engines such as Unreal have further reduced the programming expertise required to rapidly and effectively script events.

Lewis and Jacobson [69] describe another advancement. They explain the evolution of the modular game engine structure and emergence of modular simulation code, which allows for the code to be repurposed across a family of similar games.

A second area that has seen extensive advancement is the display. Early on the graphical presentation of tasks was rudimentary in terms of today's standards. Two-dimensional tasks were the norm. Today's immersive, first-person views into a simulated world were not readily available. Technological advances provided by today's engines, as described above, assist with quick scenario content development and/or implementation. This results in ever more realistic and immersive views for the users. Today's game engines provide extensive resources for researchers looking to deliver an immersive 3D environment in which research participants can act/interact. Terrain editing tools and model libraries (e.g., physics, lighting) make it feasible to produce realistic-looking environments much more quickly.

As described above, these general technological developments provided by modern game engines have advanced the suitability of serious games for team research. We consider these strengths in the following section.

\subsection{Specific advantages for team research}

Above we described characteristics of teams and challenges associated with team research. Next we considered serious games in general. We argue that advances in game engines and serious games have enabled a rich platform for team research, overcoming many of the challenges presented earlier. We now describe specific advantages we have found from our own work for using serious games in team research.

\subsubsection{The gathering and extraction of performance measures}

Early games required all performance measures be specified ahead of time so they could be programmed into the task. This was clearly a limiting factor for using serious games in team research. If additional measures of interest were desired, the programming to gather these new measures often had to start from scratch. The situation was the same if one wanted to repurpose a game. One strategy to develop performance measures had been key logging and syncing to the scenario timeline. A drawback of this approach is it requires the development of a post-processor to extract the measures of interest. This approach often required extensive programming as well. Fortunately, game engine development has made access to quantifiable data related to entities and events in a scenario much more accessible. A significant advance is that automated performance assessment is possible in today's game engines, thanks to increasingly available access to the data within the game engines. The availability of data will depend heavily on the measures of interest. For example, game engines lend themselves nicely to the collection of data related to entity locations as well as events that impact the status of entities in a scenario (e.g., munition events).

\subsubsection{The use of triggers to stimulate behavior}

Serious games can be an effective tool to elicit behavioral change [70], and in applied training environments, scenarios are scripted in a way that provides opportunities to practice learned behaviors and to demonstrate them for assessment (e.g., checklist initiation and completion, coordination with others). In team-focused research settings there are often similar requirements. 
For example, two well-known approaches for team training [coordinated awareness of situation by teams (CAST) and targeted acceptable responses to generated events or tasks (TARGETs)] involve the use of a "triggers", which is an event-based measurement approach. A pre-scripted event serves as a turning point for an individual and team to perform some targeted behaviors $([9,25,71$, 72]. With the ability to script initial conditions and behaviors, serious games are efficient at providing behavioral and event triggers and doing so in a way that is consistent across trials and participant groups, providing the necessary standardization that is so essential in research.

To further illustrate the advantages of using serious games to trigger behavior in team research, consider an example from a search-and-rescue scenario in the serious game Distributed Dynamic Decision-Making (DDD, Aptima) [73]. In one of DDD's game missions, multiple team members drive vehicles in search of a lost party. The team members are not required to drive together to achieve all of the goals in the scenario; however, to trigger cooperative behavior among team members, an automated timed message appears in their chat windows stating "Emergency Task: Flash fire damaged equipment and people (at location 201, 230) - Must be completed within 10 minutes." A scripted event, such as this emergency task, triggers cooperative behavior among team members at a specified in-game location. Again, the scripted nature of such triggers results in consistently providing an impetus to the activities researchers wish to study, in this case coordination behavior in teams.

\subsubsection{Flexible control}

As mentioned above, game engines provide the ability to script behaviors and restart scenarios to restore initial conditions. In this way, researchers running multiple teams through a series of scenarios can be certain that each team starts with the same settings. For example, consider a scenario in which events are triggered by artificial intelligence entities in the scenario. These often add required complexity, while time-based events and the initial starting conditions will be presented uniformly across participants. This enables experimental control and also assists with the comparison of pre-post measures in cases of training-focused applications and research, and/or other situations in which learning is of interest.

Furthermore, today's game engines enable researchers to easily develop parallel forms of the game levels employed in their research. Newer game engines, such as Unity Engine, allow the developer to manipulate game objects through "drag-and-drop" methods in their GUI editor. In addition to eliminating much of the computer programming knowledge that was previously necessary to create multiple forms of a game level, additional control is afforded to team researchers because the game engine editors allow the developer to create levels of varying difficulty with ease. The control offered by these game engine editors to design multiple scenarios, as similar or different to each other as necessary, is an invaluable characteristic of serious games to team researchers.

\subsubsection{Information distribution within teams:}

In many real world teams each individual only sees a piece of a problem. For example, consider an information analyst team where one member observes a feed from a satellite; a second is in situ on the ground; a third is provided content analysis from news feeds; and a fourth is monitoring real time social media posts. Team research in a laboratory setting often focuses on how individuals with unique skills, knowledge, and information can coordinate effectively, and how their team process and dynamics unfold over time. Serious games are efficient at delivering specific information to unique team members and at measuring their subsequent reactions. Scripts can also provide feedback based on individual team member reactions.

Another concern of team researchers is the recording and transcribing of communication and shared information among team members. Both voice chat and text chat are easily implemented in serious games using game engines. Of even more importance, and a feature unique to serious games, is the ability to easily record the text chat logs between participants. This feature alleviates the need to have an individual transcribe communication that occurs between team members poststudy. Not only does this save the researcher valuable time and resources, it also preserves an accurate recollection of the information shared among participants.

\subsubsection{Facilitate debriefing}

A fourth advancement of serious games used in team research is to facilitate debriefing. As pointed out by Crookall $[74,31]$ debriefing is the most important part of a game, yet it is also the most neglected. While debriefing can serve many functions these often have three primary foci [75]. The first is to capture lessons-learned and this is often employed in military and business contexts. 
Secondly, debriefing can fulfill a psychological purpose, as is the case in games where deception is part of the context set for the players. In this situation debriefing is an ethical responsibility of the researcher [76, 77]. Thirdly, debriefing can serve an educational role to facilitate learning. This is especially true if the game is constructed around principles of experience-based learning [78]. When using serious games to assist with learning, Charsky [79] advocates the use of debriefing sessions and reflective activities that are seamlessly integrated into serious games and delivered to the user upon successful completion of tasks within the game. The ability to deliver debriefing content to participants while they are still submersed in game activities provides added value to team researchers that are absent when using other methods.

Even if the primary purpose of the serious game is research, a debrief module could be constructed which takes advantage of one or more of these three principles. It is important for the researcher to consider the extent to which the game impacts future team behavior. A debriefing module can be developed to assess this aspect, centering on the three points described by Van Ments [80]: 1. Establish the facts (what happened), 2. Analyze the cause (any other possibilities), 3. Plan future action (how to apply this in the future).

Furthermore, it could be argued it is important to 'give something back' to the research participants. A debriefing module incorporating feedback in the form of video [31], observer assessment, or game playback would fulfill this function. Fortunately, there is considerable guidance from experts [75-78, 80-82] who each describe essential elements of a debrief and a model to follow when incorporating one into a serious game.

\section{Conclusions and Future Work}

Teams are ubiquitous in today's world and organizations depend upon team effectiveness for the institution's lifeblood. We reviewed essential behaviors, competencies, and components found in teams, as well as behaviors that typify adaptive teams. These characteristics of teams are relevant in both the civilian and military sectors. Team interactions often reflect the complex interplay between task-work and teamwork. The capabilities serious games pose, such as being able to represent complex environments, make them unparalleled for delivering characteristics necessary to model the complex interplay found in the real world. Advantages include being able to model the physics and kinematics of critical phenomena and to display them in realistic environments. High-resolution displays and 3D worlds, often with force feedback and similar haptic devices, further add to the realism. The use of scenario triggers to ensure the deployment of appropriate resources and to force team issues such as coordination, cooperation, and backing-up behavior is an additional advantage. Further, with flexible control, constructive agents can be deployed to interact within the scenario and with participants in meaningful ways. If scenarios extend over time, machine learning enables these agents to adapt and respond in appropriate ways to individual members as the team goes through stages of development (e.g., forming, storming, norming, performing). Serious games are uniquely positioned to deliver all the complexities necessary to create realistic worlds in which multifaceted team behaviors are to be meaningfully performed.

Research methods and paradigms must be developed to allow researchers to thoroughly explore the criterion space associated with team performance. A consideration of methodological issues relevant for team research is useful as is a classification of measures. These are provided to the reader in our review and references found in Section 2 above. Many of the real-world measures employed for individual and team performance assessment can be directly implemented in a serious game -- leading to data that is both highly reliable and internally/externally valid. The reader is referred to [60] for a recent discussion and an example employing confirmatory factor analysis subsequent to testing a latent change score structural equation model. Examples employing graph theory with teams are described in [9-11]. This type of modeling requires data with high internal and external validity. This is the other advantage serious games provide, which is the capability not only to elicit complex team behavior but also to measure it with unimpeachable reliability. Obtaining behavioral measurements with very little to no error results in the researcher being able to apply sophisticated data analytic techniques to further the theory building and theory assessment of our understanding of team performance and a team's evolution over time.

Future work should focus on a partnership between team researchers and serious game researchers. Those working in team research bring an understanding of the complexities of the milieu is which team behaviors transpire. Studying team behavior in the natural environment in which it occurs is fraught with a lack of scientific control and can lead researchers down a rabbit 
hole of spurious relationships. Alternately, studying team behavior in a lab environment, while enabling control, often lacks the realism inherent in real-world team tasks. By partnering with team researchers, serious game developers bring to the table the advantages of using a highly evolved and sophisticated tool. This platform can be utilized for research to construct highly immersive realistic task environments and scenarios whereby critical team behaviors, such as cooperation and coordination, can be elicited via scenario triggers and performance can be assessed and measured with automated performance monitors. The payoff for serious game researchers is that they can learn the intricacies of working in an area of unabashed complexities, such as those found in teams research. This additional knowledge will enable them to craft realistic scenarios that will be veridical to team members. Also serious game researchers will come to understand the necessities of how team members build relationships over time, which allow the team members to interact in effective ways to accomplish a shared goal. Development of this shared understanding between team researchers and serious game developers will enable a capability here-to-fore unmatched in traditional team research.

As defined by the Serious Games Society, “.... serious games are games designed to be more than entertaining. They are also designed to offer worthwhile learning experiences, to convince people in political or business terms, to change people's behavior or to improve people's skills or competencies." [83]. These indeed are useful applications and lofty goals; yet we believe serious games can have a more pervasive impact. We argue serious games are an effective tool for research and this is especially true when the research of interest demands an exploration of complex relations, as is the case for teams working in today's high stakes military and corporate environments. Thus, the time has come for those who do research on teams to embrace a technology that can arguably provide more useful insights into their problem domain than any traditional methodological technique; and for those who work with serious games to extend their reach into research, and by focusing on team research can make substantial contributions to an area in need of their skills while making foundational contributions to the organizations of today and the employees of tomorrow.

\section{References}

[1] Townsend, A. M., DeMarie, S. M., \& Hendrickson, A. R. Virtual teams: Technology and the workplace of the future. The Academy of Management Executive, 12(3), 17-29, 1998. https://doi.org/10.5465/ame.1998.1109047

[2] Coovert, M. D. Technological changes in office jobs: What we know and what we can expect. In A. Howard (Ed.), The changing nature of work: Frontiers of industrial and organizational psychology (pp. 175-208). San Francisco, CA: Jossey-Bass, 1995.

[3] Coovert, M. D., \& Foster Thompson, L. F. Computer-supported cooperative work: Issues and implications for workers, organizations, and human resource management. Thousand Oaks, CA: Sage, 2001.

[4] Coovert, M. D. and Foster Thompson, L. (Eds.) The Psychology of Workplace Technology. New York, NY: Routledge Taylor \& Francis Group, 2014.

[5] Pavlova, E., Coovert, M. D., \& Bennett, W. Trust development in computer-mediated teams: A latent change score model. Multivariate Behavioral Research, 48, 166-167, 2013. https://doi.org/10.1080/00273171.2013.752265

[6] Cooke, N. J., Kiekel, P. A., Salas, E., Stout, R., Bowers, C., \& Cannon-Bowers, J. A. Measuring team knowledge: A window to the cognitive underpinnings of team performance. Group Dynamics: Theory, Research, and Practice, 7 (3), 179-199, 2003. https://doi.org/10.1037/1089-2699.7.3.179

[7] Brannick, M.T., Roach, R.M., \& Salas, E. Understanding team performance: A multidimensional study. Human Performance, 6(4), 287-308, 1993. https://doi.org/10.1207/s15327043hup0604_1

[8] Dickenson, T.L., \& McIntyre, R.M. A conceptual framework for teamwork measurement. Team performance assessment and measurement (19-43). In M.T. Brannick, E. Salas, C.W. Prince (Eds.), Team performance assessment and measurement: Theory, methods, and applications. Taylor \& Francis, 1997.

[9] Coovert, M. D. Petri nets: Modeling the complexity of modern jobs. In J. M. Cortina and R. S. Landis (Eds.), Modern research methods for the study of behavior in organizations (pp. 381404). New York, NY: Routledge Taylor \& Francis Group, 2013. 
[10] Coovert, M. D., Salas, E., \& Cannon-Bowers, J. A. Process models of team behavior. Proceedings of the American Control Conference. IEEE Press, 1991.

[11] Yagoda, R. E., \& Coovert, M. D. How to work and play with robots: An approach to modeling human-robot interaction. Computers in Human Behavior, 28(1), 60-68, 2012. https://doi.org/10.1016/j.chb.2011.08.011

[12] Marks, M.A., Mathieu, J.E., \& Zaccaro, S.J. A temporally based framework and taxonomy of team processes. Academy of Management Review, 26(3), 356-376, 2001.

[13] LePine, J.A., Piccolo, R. F., Jackson, C. L., Mathieu, J. E., \& Saul, J. R. A meta-analysis of teamwork process: Tests of a multidimensional model and relationships with team effectiveness criteria. Personnel Psychology, 61(2), $273-307,2008$. https://doi.org/10.1111/j.1744-6570.2008.00114.x

[14] Cooke, N.J., Salas, E., Cannon-Bowers, J. A., \& Stout, R. J. Measuring team knowledge. Human Factors, 42, (1), 151-173, 2000. https://doi.org/10.1518/001872000779656561

[15] Klimoski, R. \& Mohammed, S. Team mental model: Construct or metaphor? Journal of Manage,ent, 20, 403-437, 1994.

[16] Langan-Fox, J., Anglim, J. \& Wilson, J. R. Mental models, team mental models, and performance: Process, development, and future directions. Human Factors and Ergonomics in Manufacturing, 14(4), 331-352, 2004. https://doi.org/10.1002/hfm.20004

[17] Mohammed, S. \& Dumville, B. C. Team mental models in a team knowledge framework: Expanding theory and measurement across disciplinary boundaries. Journal of Organizational Behavior, 22, 89-106, 2001. https://doi.org/10.1002/job.86

[18] Mohammed, S., Klimoski, R. \& Rentsch, J. R. The measurement of team mental models: We have no shared schema. Organizational Research Methods, 3(2), 123-165, 2000. https://doi.org/10.1002/job.86

[19]Hess, K. P., Freeman, J., \& Coovert, M. D. CENTER: Critical thinking in team decision making. In M. P. Letsky, N. W. Warner, S. M. Fiore, \& C.A.P. Smith (Eds.). Macrocognition in teams: Theories and methodologies (pp. 239-258). Burlington, VT: Ashgate Publishing, 2008.

[20]Rosen, M.A., Bedwell, W.L., Wildman, J. L., Fritzsche, B.A., Salas, E, \& Burke, C.S., Managing adaptive performance in teams: Guiding principles and behavioral markers for measurement. Human Resource Management Review, 21, 107-122, 2011. https://doi.org/10.1016/j.hrmr.2010.09.003

[21]Burke, C.S., Stagl, K.C., Klein, C., Goodwin, G.F., Salas, E., \& Halpin, S.M. What type of leadership behaviors are functional in teams? A meta-analysis. Leadership Quarterly, 17, 288307, 2006. https://doi.org/10.1016/j.leaqua.2006.02.007

[22] Tuckman, B.W. Developmental sequence in small groups. Psychological Bulletin, 63(6), 384399, 1965. https://doi.org/10.1037/h0022100

[23] Morgan, Jr. B.B., Glickman, A.S., Woodard, E.A. Blaiwes, A.S., \& Salas, E. Measurement of team behaviors is a Navy environment. Battell Columbus Labs, Research Triangle Park, NC, 1986.

[24] Prince, C., \& Salas, E. Training and research for teamwork in the military aircrew (337-366). In E. L. Wiener, B. G. Kanki, and R.L. Helmreich (Eds.), Cockpit resource management, Elsevier, 1993.

[25] Fowlkes, J. E., Lane, N.E., Salas, E., Franz, T., \& Oser, R., Improving the measurement of team performance: The TARGETs methodology. Military Psychology, 6(1), 47-61, 1994. https://doi.org/10.1207/s15327876mp0601_3

[26]Herz, J. C., \& Macedonia, M. R. (2002). Computer games and the military: Two views. Defense Horizons, (11-12), 1.

[27] Shilling, R., Zyda, M., \& Wardynski, E. C. (2002, November). Introducing Emotion into Military Simulation and Video Game Design America's Army: Operations and VIRTE. In GAME-ON.

[28] Moon, I. C., Schneider, M., \& Carley, K. M. (2006). Evolution of player skill in the America's army game. Simulation, 82(11), 703-718. https://doi.org/10.1177/0037549706073689

[29]Farrell, C. M., W. K. Klimack, and C. R. Jacquet. 2003. Employing interactive multimedia instruction in military science education at the U.S. Military Academy. In Proceedings of the Interservice/Industry Training, Simulation, and Education (I/ITSEC) Conference, Orlando, FL.

[30] Alhadeff, E. (2016), Serious Games Market. Retrieved Feb 3, 2017 from: http://seriousgamesmarket.blogspot.com/2016/12/2016-winners-announced-seriousgames.html 
[31] Crookall, D. Serious games, debriefing, and simulation/gaming as a discipline. Simulation \& Gaming, 41(6), 898-920, 2010. https://doi.org/10.1177/1046878110390784

[32] de Freitas, S., \& Ketelhut, D.J. Introduction to the Journal of Information Sciences special issue on serious games. Information Sciences, 264, 1-3, 2014. https://doi.org/10.1016/j.ins.2014.01.036

[33] Greco, M., Baldissin, N., \& Nonino, F. An exploratory taxonomy of business games. Simulation \& Gaming, 44(5), 645-682, 2013. https://doi.org/10.1177/1046878113501464

[34] MONOPOLOGS [Developed by Rand Logistic Department.] Santa Monica: CA. Rand Corporation, 1955.

[35] Abt, C.A. Serious games. Viking, New York, 1970.

[36]Faria, A.J. The changing nature of business simulation/gaming research: A brief history. Simulation \& Gaming, 32(1), 97-110, 2001. https://doi.org/10.1177/104687810103200108

[37]Bragge, J., Thavikulwat, P., \& Töyli, J. Profiling 40 years of research in Simulation \& Gaming. Simulation \& Gaming, 41(6), 869-897, 2010. https://doi.org/10.1177/1046878110387539

[38] Feinstein, A. H., \& Cannon, H. M. Constructs of simulation evaluation. Simulation \& Gaming, 33(4), 425-440, 2002. https://doi.org/10.1177/1046878102238606

[39] Sauvé, L., Renaud, L., Kaufman, D., \& Marquis, J.S. Distinguishing between games and simulations: A systematic review. Educational Technology \& Society, 10(3), 247-256, 2007.

[40] Pohl, A., \& Walker, J. Leveraging game technology: Where are games the right answer to augment military training? Material Science \& Technology, 2, 22-26, 2010.

[41] Werbach, K., \& Hunter, D. For the win: How thinking can revolutionize your business. Wharton Digital Press: Philidelphia, 2012.

[42] Deterding, S., Dixon, D., Khaled, R., \& Nacke, L. From game design elements to gamefullness: Defining "gamification". Proceedings of the 15th International Academic MindTrek Conference: Envisioning Future Media Environments. Tampere, Finland, 2011. https://doi.org/10.1145/2181037.2181040

[43] Bailey, P., Pritchard, G., \& Koenohan, H. Gamification in market research: Increasing enjoyment and richness of data, but what of data validity? International Journal of Market Research, 57 (1), 17-28, 2015. https://doi.org/10.2501/IJMR-2015-003

[44] Deterding, S. Gamification: Designing for motivation. Interactions, 19(4), 14-17, 2012. https://doi.org/10.1145/2212877.2212883].

[45]Paharia, R. Gamification means applying intrinsic value, 19(4), 14-17, 2012. https://doi.org/1010,1145/2212877.2212883]

[46]Landers, R.N., \& Landers, A.K. An empirical test of the theory of gamified learning: The effect of leaderboards on time-on-task and academic performance. Simulation \& Gaming, 45(6), 769-785, 2015. https://doi.org/10.1177/1046878114563662

[47] Mitgutsch, K., \& Alvarado, N. Purposeful by design? A serious game design assessment framework. Proceedings of Foundations of Digital Games (121-128). Association for Computing Machinery, Raleigh: N.C., 2012.

[48] Salen, K., \& Zimmerman, E. Rules of play: Game design fundamentals. Cambridge: MIT Press, 2003.

[49]De Gloria, A., Bellotti, F., \& Berta, R. (2014). Serious games for education and training. International Journal of Serious Games, 1(1). https://doi.org/10.17083/ijsg.v1i1.11

[50] Connolly, T.M., Boye, E.A., MacArthur, E., Hainey, T., \& Boyle, J.M. A systematic literature review of empirical evidence on computer games and serious games. Computers \& Education, 59, 661-686, 2012. https://doi.org/10.1016/j.compedu.2012.03.004

[51] Ortiz, S. (2015). Video game self-efficacy and its effect on training performance. International Journal of Serious Games, 2(3). https://doi.org/10.17083/ijsg.v2i3.89

[52] Sitzmann, T. A meta-analytic examination of the instructional effectiveness of computer-based simulation games. Personnel Psychology, 64, 489-528, 2011. https://doi.org/10.1111/j.17446570.2011.01190.x

[53] Bedwell, W.L., Pavlas, D., Heyne, K., Lazzara, E. H., \& Salas, E. Toward a taxonomy linking game attributes to learning: An empirical study. Simulation \& Gaming, 43(6), 729-760, 2012. https://doi.org/10.1177/1046878112439444

[54]Landers, R.N. Developing a theory of gamified learning: Linking serious games and gamification of learning. Simulation \& Gaming, 45(6), 752-768, 2015. https://doi.org/10.1177/1046878114563660 
[55] Ghannem, A. Characterization of serious games guided by the educational objectives. Proceedings of TEEM'14 (pp. 227-233). Association for Computing Machinery, 2014. https://doi.org/10.1145/2669711.2669904

[56] Mayer, I., Bekebrede, G., Harteveld, C., Warmelink, H., Zhou, Q., van Ruijven, T., Lo, J., Kortmann, R., \& Wenzler, I. The research and evaluation of serious games: Toward a comprehensive methodology. British Journal of Educational Psychology, 45(3), 502-527, 2014. https://doi.org/10.1111/bjet.12067

[57] de Klerk, S., Veldkamp, B.P., \& Eggen, T.J.H.M. Psychometric analysis of the performance data of simulation-based assessment: A systematic review and a Bayesian network example. Computers \& Education, 85, 23-34, 2015. https://doi.org/10.1016/j.compedu.2014.12.020

[58] Chorianopoulos, K., Giannakos, M.N., \& Chrisochoides, N. Design principles for serious games in mathematics. Proceedings of the 18th Panhellenic Conference on Informatics (pp. 15). Association for Computing Machines, 2014. https://doi.org/10.1145/2645791.2645843

[59] Margolis, M.J., \& Clauser, B.E. A regression-based procedure for automated scoring of a complex medical performance assessment. In. D.M. Williamson, I. I. Bejar, and R.J. Mislevy (Eds.), Automated scoring of complex tasks in computer-based testing (pp. 123-168). Mahwah, NJ: Lawrence Erlbaum Associates, 2006.

[60] Coovert, M. D., Winner, J., \& Bennett, W. Construct development and validation in gamebased research. Simulation \& Gaming, 47(6),1-13, 2016. https://doi.org/10.1177/1046878116682661

[61] Mäyrä, F., Holopainen, J., Jakobsson, M. Research methodology in gaming: An overview. Simulation \& Gaming, 43(3), 295-299, 2012. https://doi.org/10.1177/1046878112439508

[62] de Caluwé, Geurts, J., \& Kleinlugtenbelt, W.J. (2012). Gaming research in policy and organization: An assessment from the Netherlands. Simulation \& Gaming, 43(5), 600-626. https://doi.org/10.1177/1046878112439445

[63]Eladhari, M.P., \& Ollila, E.M.I. Design for research results: Experimental prototyping and play testing. Simulation \& Gaming, 43(3), 391-412, 2012. https://doi.org/10.1177/1046878111434255

[64] Protopsaltis, A., \& Auneau, L. Scenario-based serious game repurposing. Proceedings of the 29th ACM International Conference of Design of Communications (37-43). Association for Computing Machinery, 2011. https://doi.org/10.1145/2038476.2038484

[65] Campbell, D.T., \& Fiske, D.W. Convergent and discriminant validation by the multitraitmultimethod matrix. Psychological Bulletin, 56(2), 81-105, 1959. https://doi.org/10.1037/h0046016

[66] Widaman, K.F. (1985). Hierarchically nested covariance structure models for multitraitmultimethod data. Applied Psychological Measurement, 9(1), 1-26, 1985. https://doi.org/10.1177/014662168500900101

[67] Jöreskog, K. G. A general approach to confirmatory maximum likelihood factor analysis. Psychometrika, 34(2), 183-202, 1969. https://doi.org/10.1007/BF02289343

[68] Marsh, H.W., Balla, J.R., \& McDonald, R.P. Goodness-of-fit indexes in confirmatory factor analysis: The effect of sample size. Psychological Bulletin, 103(3), 391-410, 1988. https://doi.org/10.1037/0033-2909.103.3.391

[69] Lewis, M., \& Jacobson, J. Game engines in scientific research. Communications of the ACM, 45(1), 27-31, 2002.

[70] Hendrix, M., Al-Sherbaz, A., \& Victoria, B. (2016). Game based cyber security training: are serious games suitable for cyber security training?. International Journal of Serious Games, 3(1). https://doi.org/10.17083/ijsg.v3i1.107

[71] Gorman, J. C., Cooke, N. J., Pederson, H. K., Connor, O. O., \& DeJoode, J. A. Coordinated awareness of situation by teams (CAST): Measuring team situation awareness of a communication glitch. Proceedings of the Human Factors and Ergonomics Society 49th Annual Meeting,Orlando, FL, 274-277, 2005. https://doi.org/10.1177/154193120504900313

[72] Gorman, J. C., Cooke, N. J., \& Winner, J. L. Measuring team situation awareness in decentralized command and control environments. Ergonomics, 49(12-13), 1312-1325, 2006 https://doi.org/10.1080/00140130600612788

[73] Aptima, Inc. Distributed Dynamic Decision-making: The DDD Team simulation. https://github.com/aptima/ddd (2005)

[74] Crookall, D. Debriefing. Simulation \& Gaming, 23(2), 141-142, 1992. https://doi.org/10.1177/1046878192232001

[75]Lederman, L.C. Debriefing: Toward a systematic assessment of theory and practice. Simulation \& Games, 23(2), 145-160, 1992. https://doi.org/10.1177/1046878192232003 
[76] Stewart, L.P. Ethical issues in postexperimental and postexperiential debriefing. Simulation \& Gaming, 23(2), 196-211, 1992. https://doi.org/10.1177/1046878192232007

[77] APA Ethical principles of psychologists and code of conduct. American Psychological Association. APA, Washington D.C, 2010.

[78] Lederman, L.C. Debriefing: A critical reexamination of the postexperience analytic process with implications for its effective use. Simulation \& Games, 15(4), 415-431, 1984. https://doi.org/10.1177/0037550084154002

[79] Charsky, D. From edutainment to serious games: A change in the use of game characteristics. Games and culture, 5(2), 177-198, 2010. https://doi.org/10.1177/1555412009354727

[80] Van Ments, M. The effective use of role-play. London: Kogan Page, 1989.

[81] Steinwachs, B. How to facilitate a debriefing. Simulation \& Gaming, 23(2), 186-195, 1992. https://doi.org/10.1177/1046878192232006

[82] Thiagarajan, S. Using games for debriefing. Simulation \& Gaming, 23(2), 161-173, 1992. https://doi.org/10.1177/1046878192232004

[83] Academy, Serious Games Society. http://academy.seriousgamessociety.org/about. Retrieved March 15, 2017. 